\title{
Gritos de África II Foro Mundial de Teología y Liberación
}

\section{Agenor Brighenti* Brasil}

En la senda del Foro Social Mundial, que acaba de celebrar su séptima edición, nació el Foro Mundial de Teología y Liberación, que, por su parte, acaba de celebrar su segunda edición. A primera vista, la distancia entre la creación de ambos foros podría sugerir que la Iglesia va a remolque de la historia. La verdad es, más bien, que muestra la sintonía de la comunidad teológica internacional con los desafíos del momento.

En este artículo, queremos ofrecer dos reflexiones como aporte a la comprensión y el futuro de dicho Foro. En una primera parte haremos, a la manera de crónica, una reflexión sobre elementos que hay que tener en cuenta del II Foro Mundial de Teología y Liberación, que tuvo lugar en Nairobi: el evento en sí mismo, la programación, el apoyo organizativo y dos momentos trascendentales del encuentro. En una segunda parte - dejando que el Foro siga resonando en la mente y en el corazón-, intentaremos poner en palabra el grito, siempre sofocado, de África, una realidad en muy buena medida desconocida y olvidada. Este grito se dirige a la racionalidad occidental y a los privilegiados de un planeta enfermo, también a los pobres y excluidos de un mundo donde no caben todos. Y se dirige también a la Iglesia, a la teología, a los teólogos.

* El autor es doctor en teología por la Universidad de Lovaina, brasileño, profesor de teología, en su país y en México, presidente del Instituto Nacional de Pastoral de la Conferencia de Obispos de Brasil y miembro del Comité Organizador del Foro Mundial de Teología y Liberación, en representación de Amerindia. 


\section{Elementos para una crónica del Foro}

\subsection{El evento}

El II Foro Mundial de Teología y Liberación tuvo lugar en Nairobi los días 16 y 19 de enero de 2007. El primero había tenido lugar en Porto Alegre, en enero de 2005, cuyos resultados están publicados en L. C. Susin (org.), Teologia para outro mundo possível (São Paulo: Ed. Paulinas, 2006, 485 págs.). El tema del segundo Foro fue la "Espiritualidad para otro mundo posible". Se hicieron presentes trescientos participantes, provenientes de los cinco continentes, en su mayoría de África, sobre todo de Nairobi, seguida de Europa, América, Asia y Oceanía, respectivamente. Más allá de la reflexión y de los contenidos, el mero encuentro e intercambio de búsquedas y realizaciones, en el nivel planetario, ya justifica, por sí mismo, la reunión. En tiempos de crisis de paradigmas y metarrelatos, la experiencia se erige en lugar privilegiado para repensar la razón y las razones de existir, del mundo y de la fe. Los trabajos se efectuaron en el Carmelite Center, en los alrededores de la contrastante capital de Kenia. Al igual que el primero, el segundo Foro Mundial de Teología y Liberación tuvo lugar la semana anterior al Foro Social Mundial, que llegaba a su séptima edición, todas ellas exitosas.

Como no podía ser de otra manera, el continente africano dio la tónica al Foro, no sólo por la amplia mayoría de participantes y conferencistas, sino, sobre todo, por su riqueza cultural y religiosa, y por los gigantescos desafíos socio-económicos, que plantea con crudeza su interpelante realidad. Junto a la vitalidad y el coraje de su gente, se hizo presente la miseria de un África olvidada, una herida abierta y expuesta de forma agresiva, aunque siempre suavizada por la esperanza y la alegría, la amabilidad y serenidad de su gente. Por lo que toca a los keniatas, por un lado, el incipiente transporte público y el costoso transporte privado los obliga a caminar una decena de kilómetros diariamente, y por otro lado, el andar solitario y silencioso les permite el procesamiento de una estética interior envidiable, estampada en el espíritu de determinación y en sus cuerpos esbeltos, de trazos precisos, esculturales. "Otro mundo", ante todo necesario y también posible, depende mucho de la contribución de África, portadora de las mayores reservas de resistencia y esperanza del planeta. Asimismo, "otra Iglesia posible" pasa por su religiosidad, unida a la vida, en profundo respeto a sus tradiciones ancestrales.

\subsection{La programación}

En el Foro hubo conferencias, paneles, seminarios, comunicaciones, así como participación directa en prácticas eclesiales liberadoras y la inserción en las periferias de Nairobi.

Por lo que toca a las conferencias y los paneles, el objetivo era hacer un diagnóstico de la realidad socio-económica global y de la realidad socio-religio- 
sa africana, con la finalidad de identificar las consecuencias para las religiones, las iglesias y las teologías, y, desde ahí, preguntarse sobre qué espiritualidad deben apoyarse las prácticas religiosas. Los autores de estas reflexiones fueron, entre otros, François Houtart (Bélgica); Tinyiko Maluleke, John Mary Walligo, Philomena Mwaura, L. Magesa y Tereza Okure (África); Rohan Silva (Asia); Jon Sobrino y Eunice Santa de Valéz (América Latina); y J. J. Tamayo (Europa).

Quince comunicaciones sobre búsquedas, investigaciones y experiencias trataron temas en torno al feminismo, el fundamentalismo, el diálogo interreligioso y el compromiso social, en el contexto de la globalización.

Los seminarios, veinticuatro, trataron otros temas, como ecología, culturas, espiritualidad, el SIDA, la teología, el imperialismo, la teología india y la democracia.

Un momento fuerte del Foro consistió en acercarse a las prácticas de cristianos, en barriadas pobres, orfanatos e iniciativas de promoción humana y desarrollo integral. Una de esas barriadas, Kibera, con setecientos mil habitantes, la mayor de África, conmovió a los visitantes, por la increíble miseria de las condiciones de vida, y por la creatividad de su gente y el heroísmo de las iniciativas pastorales.

Otro momento fuerte fue la conferencia del arzobispo Desmond Tutu, que cerró con llave de oro los trabajos del Foro. Fue una hora, extremadamente corta, fulgurante por la elocuencia de su testimonio de profeta frente al aparteid, llena de humor, mística bíblica, profundidad teológica y sincero amor a los pobres y excluidos.

\subsection{Elementos para una evaluación}

\subsubsection{La metodología y la dinámica de trabajo}

Con ocasión del primer Foro Mundial de Teología y Liberación, en Porto Alegre, en el año 2005, la gran crítica fue su carácter académico, que le dio un perfil, más de un simposio de profesionales, que de un foro realmente con carácter popular.

Siguiendo la sugerencia de los participantes de aproximar la metodología del Foro de Teología a la del Foro Social, el Foro de Nairobi hizo profundos cambios, tanto en la dinámica de los trabajos como en la convocatoria de los participantes. En lugar de un grupo restringido de académicos, la mayoría de los presentes en el segundo Foro eran personas ligadas a prácticas populares. Por su parte, los paneles, las comunicaciones, los seminarios y las inserciones en la realidad concreta del lugar ofrecieron un carácter dinámico, de actualidad y de interacción entre los presentes, con discusiones, en ciertos momentos acaloradas. Incluso las conferencias abandonaron un tono puramente sistemático para intentar reflexionar teológicamente sobre los problemas del momento. 
El alcance de esta metodología fue limitado, pues "prácticas alternativas requieren igualmente un pensamiento alternativo" (Boaventura dos Santos), lo que aún está por conseguirse. No podía ser de otro modo. Con una nueva metodología también se paga un precio y se corren riesgos. En el Foro de Nairobi, para los participantes oriundos de medios académicos "hubo mucha liberación y poca teología", y para los provenientes de trabajo de base "hubo mucha religión y poca liberación".

El desafío para el tercer foro será promover la interacción entre prácticas populares y reflexión teológica, entre agentes de pastoral y teólogos profesionales, los cuales, dicho sea de paso, estuvieron bastante ausentes, en este segundo foro. Aun cuando no actúen directamente en las mesas de trabajo, es preciso garantizar la presencia de por lo menos unos cinco teólogos profesionales de cada continente, porque en este nivel de la reflexión es donde los retos de la realidad son elevados a concepto y son propiamente teologizados. Para que haya avances en los foros, se necesita también del trabajo profesional de sistematización.

\subsubsection{Los contenidos}

La propuesta del Foro de Nairobi era centrarse en la "espiritualidad para otro mundo posible". Sin embargo, el tema quedó, en buena medida, en la penumbra - y con ello la teología-, oscurecido por las grandes cuestiones socio-económicas, culturales y ambientales, tales como aparecen en el Foro Social. Como contrapartida, no hubo riesgo de elaborar una teología huérfana de realidad social, aunque ciertas posiciones de algunos de los presentes tendiesen a dejarla huérfana de Iglesia y hasta de religión.

En los futuros foros de teología hay que evitar dos extremos. Por un lado, evitar el riesgo de que el Foro de Teología se convierta en una mera caja de resonancia del Foro Social Mundial, lo cual sería competir y duplicar esfuerzos. Por otro, evitar el riesgo de una teología híbrida, situada entre una filosofía o sociología de la religión y una mística holista. En el futuro, es necesario que la teología no descuide su propia entidad, lo cual es una dificultad específica, cuando intenta articularse desde el actual pluralismo cultural y religioso.

Sobre esto último, con razón, ha insistido Jon Sobrino en que, en el esfuerzo por tejer redes y establecer puentes entre diferencias, en lugar de buscar "mínimos comunes", hay que tener ante los ojos los "máximos verdaderos" de cada uno, en el amor a su propio pueblo oprimido. El "mínimo común" será siempre muy poco y muy débil para revertir este mundo. El "máximo" consiste en que cada religión profundice en lo mejor que tiene como propio, lógicamente antes de pensar en que va a transformar este mundo. El "máximo" de cada uno, juntos todos ellos, puede infinitamente más que los "mínimos comunes". 
La gran sintonía necesaria para la transfiguración de este mundo no acaece en torno a unos conceptos determinados, sino en una acción común, capaz de revertir la situación de un homo demens, en un planeta enfermo.

\subsubsection{El tema específico de la espiritualidad}

Desafortunadamente, las comunicaciones y los seminarios se centraron poco en el tema específico del Foro, que era la espiritualidad. Las conferencias y los paneles buscaron articular las cuestiones planteadas por el mundo de hoy, más con la globalidad de la teología que, en concreto, con la espiritualidad. El panel final, cuyo objetivo era formular las conclusiones de la discusión, en la esfera de la espiritualidad, no llegó a tematizarla teológicamente, aunque sí intentó colocar los problemas de hoy dentro de la espiritualidad.

Queda la duda de si un foro mundial, que no es un simposio, puede centrarse en un tema específico, o si más bien, debe estar abierto a la globalidad de las cuestiones que vienen del mundo, de las iglesias y las religiones. En el caso de que se deje el abanico tan abierto, no se deberá esperar del foro una reflexión teológica muy sistemática. Es la misma realidad con la cual se enfrenta el Foro Social Mundial. Se constituye en "espacio" multitemático y multifacético, de reflexión comprometida y militante, pero sin pretender desembocar en conclusiones y acuerdos comunes sobre realidades específicas, que ocurre de modo tan diverso y particular. La universalidad de los desafíos no favorece la pretensión de uniformidad de las respuestas.

\subsubsection{Perspectivas de futuro para el Foro}

Por más que el comité organizador tenga experiencia en eventos de esta naturaleza, sólo en el propio caminar se podrán ir perfeccionando la metodología, las dinámicas, el tenor de las discusiones y, en consecuencia, los resultados. Ya hay dos evaluaciones que orientarán el rumbo del próximo Foro. Una, la de los participantes, hecha al final de los trabajos. Otra, la del comité internacional, responsable del encuentro, que se reunió al día siguiente de la clausura. En estas evaluaciones aparecen las siguientes recomendaciones.

Una de ellas es la de continuar aproximando la metodología del Foro de Teología y Liberación a la metodología del Foro Social Mundial, y que, por lo tanto, no cabe esperar de él mucha profundidad en la reflexión, ni mucha sistematización de los contenidos. Se piensa que es importante privilegiar la reunión como un espacio donde emerjan nuevas intuiciones que se desprenden de prácticas significativas. Para que esto no resulte frustrante a quienes buscan avances en la reflexión, conviene asegurar la presencia de un cierto número de teólogos profesionales, capaces de ir haciendo, al interior del propio Foro, la relación entre acción y reflexión. 
Otra recomendación se refiere a mantener en el programa de los próximos foros la inserción concreta de los participantes en realidades populares, que intentan prácticas liberadoras. Esta fue la gran novedad del Foro de Nairobi, la cual tuvo fuerte impacto sobre su posterior reflexión. Se llegó a decir que si las visitas a experiencias significativas fuesen colocadas más al inicio de los trabajos, el efecto sería todavía más positivo. Como se trata de un foro de teología y liberación, no se debe perder de vista que la teología es un acto segundo, precedido por el acto primero de la práctica liberadora de la fe. Antes de la teología viene la liberación. Un "foro mundial" no puede perder de vista el "mundo real" (Jon Sobrino) y, dentro de él, la realidad desnuda y cruda de los pobres. No basta que la Iglesia proponga insertarse dentro del mundo. Es necesario preguntarse dentro de qué mundo (Gustavo Gutiérrez). ¿Del mundo del 20 por ciento de los privilegiados o del mundo del 80 por ciento de los excluidos? Del lado de éstos está la óptica evangélica para leer la totalidad de la realidad, que se constituyó en el principio hermenéutico de una teología exenta de cinismo ante el sufrimiento del pobre. En confrontación directa con el mundo de los crucificados, nuestra tarea de transfiguración de todo lo que se encuentra desfigurado aparece de forma histórica y concreta.

Una tercera recomendación importante se refiere a la necesidad de clarificar mejor los objetivos del Foro de Teología y Liberación. Se sugirieron tres. Primero, ser un espacio de encuentro para teólogos que trabajan en la perspectiva de la liberación; segundo, propiciar la interacción entre prácticas liberadoras y sus agentes y la reflexión teológica; y tercero, constituirse en un esfuerzo de presencia pública de la teología, en el seno de la sociedad, más allá del espacio eclesial o confesional. Sin duda, en un mundo globalizado, la producción teológica no ha de restringirse a los retos de una determinada región. La mundialización universaliza igualmente retos, otrora regionales. Se amplía el horizonte de una teología contextualizada. Por eso, es preciso escuchar diferencias y articular un discurso más narrativo de experiencias concretas, que de conceptualizaciones académicas. Es momento de que la teología vuelva a detenerse con nueva mirada sobre lo pre-teológico, en las prácticas liberadoras de la fe que han cambiado sustancialmente, en los últimos tiempos. Y, desde allí, asumir su papel profético en el seno de una sociedad, carente de voces y prácticas, que sean motivo para que los pobres puedan seguir esperando.

Una cuarta recomendación tiene que ver con la periodicidad del Foro. En el seno del comité internacional hubo voces que se pronunciaron en favor de su realización cada cuatro años, por dos razones: una, por el hecho de la mayor lentitud de la reflexión teológica, en relación a los acontecimientos socio-culturales, en un mundo en acelerado proceso de transformación; otra, por el peso que cae sobre los miembros del comité organizador, encargado de la organización y la búsqueda de financiamiento. No obstante, para la mayoría de los miembros del 
comité, el Foro debería realizarse cada dos años, por lo menos hasta que su metodología esté mejor diseñada y consolidada. Y además, a ejemplo del Foro Social, es necesario ir creando una mentalidad favorable a la realización de foros locales y regionales. Ahí sí se podría pensar en la realización de foros mundiales cada cuatro años. También se planteó la hipótesis de efectuar el foro de teología después del foro social, sobre todo para propiciar la participación, ya financiada, de más gente. Con todo, se optó por mantenerlo en la semana anterior, para no dispensar a la teología de la obligación de ser creativa y para no hacer de los teólogos meros intérpretes y comentadores de lo que pasa en el Foro Social Mundial.

\subsubsection{El apoyo organizativo}

Como toda iniciativa de tal envergadura, el apoyo organizativo se va diseñando en el caminar, de acuerdo con las necesidades y posibilidades que se presentan. Hasta el momento, cuatro estructuras han apoyado a los foros: un comité internacional, promotor del evento; el secretariado permanente, con sede en Porto Alegre; un comité local temporal, constituido en el lugar donde se realiza el encuentro; y un grupo de entidades de apoyo, que garantice su financiamiento. Con la celebración del segundo foro, la experiencia apuntó a la necesidad de una reestructuración de la organización. Continúan existiendo los comités internacional y local, así como el grupo de entidades de apoyo. Sin embargo, se decidió reforzar el trabajo del secretariado permanente. Este pasa ahora a ser el comité organizador, integrado por instituciones académicas próximas a Porto Alegre y por Amerindia, respaldado por un comité consultivo, constituido por personas inspiradoras del Foro.

La realización del Foro de Nairobi se asentó sobre tres estructuras: el secretariado permanente, que contó con el eficiente trabajo de Luiz Carlos Susin, respaldado por la experiencia de Sergio Torres, inspirador, junto con Leonardo Boff, del Foro Mundial; el comité local, presidido por Mary N. Getui, impecable en la organización, logística y coordinación de los trabajos; y un comité teológico, que ayudó a resumir las reflexiones durante el evento, integrado por L. Magesa, Tereza Okure, K. C. Abraham y Eugene Goussikendey (África); Diego Irarrázabal y Agenor Brighenti (América Latina); J. J. Tamayo (Europa) y Denise Couture (Canadá).

\subsection{Dos momentos fundamentales del Foro}

No podríamos terminar este relato sobre el segundo Foro Mundial de Teología y Liberación, en Nairobi, sin un breve comentario sobre dos momentos trascendentales: la visita a Kibera y Gorogocho, y la presencia y alocución del arzobispo surafricano Desmond Tutu, quien cerró los trabajos del Foro. 


\subsubsection{La visita a Kibera y Gorogocho}

El Foro de Teología y Liberación de Nairobi se abrió con un análisis de la realidad socio-económica global, a cargo de François Houtart. Llamó la atención sobre la lógica nefasta del sistema liberal-capitalista globalizado, basado en el "consenso de Washington": libertad de mercado, en un mundo desigual, con ventaja para el más fuerte, en una especie de darwinismo social. Las consecuencias más dramáticas son el desempleo, el desmantelamiento del sindicalismo, el Estado como un costo y no como un servicio, el saber (universidades) en función del lucro (multinacionales), el desastre ecológico, la militarización del planeta por el control de los recursos naturales y, en el plano cultural, el individualismo como un valor supremo, entre otras.

El resultado es un escándalo: en un 20 por ciento de la población mundial se concentra el 82.7 por ciento de la renta, mientras que el restante 80 por ciento solamente recibe el 17.3 por ciento de la renta. A pesar de eso, muchos piensan —incluida la enseñanza social de la Iglesia - que el sistema liberal-capitalista puede ser humanizado, reformado, cuando la única salida es deslegitimarlo. Una esperanza es la creciente resistencia en el mundo entero, tal como se manifiesta en el Foro Social Mundial. La salida es crear una voluntad política y pasar de la conciencia a la acción, a través de un nuevo sujeto histórico de la proporción de una sociedad civil mundial.

No obstante el dramatismo de este análisis, es muy diferente oírlo en una sala, sentados en confortables butacas, equipada con todos los recursos audiovisuales modernos, entre personas pertenecientes al 20 por ciento de los privilegiados, que ver con los propios ojos la realidad desnuda y cruda del 80 por ciento de los excluidos.

Pues bien, el Foro de Nairobi expuso a sus participantes al choque de esta realidad, organizando una tarde de convivencia con contingentes humanos, escoria de la humanidad. Nairobi cuenta con un millón y medio de habitantes, la mitad de los cuales se reparten apenas el 5 por ciento del territorio, en las barriadas miserables de Kibera y Gorogocho. Se dice que en Kibera, la mayor barriada miserable de África, viven setecientas mil personas en el interminable amontonamiento de chozas de barro cubiertas de zinc, cortado por callejuelas que, además de vías para caminar, sirven de basurero, lugar de comercio, de paseo, de escurridero de la cloaca a cielo abierto, de la conversación gratuita y alegre, de audición de música, etc. No hay agua entubada, ni luz eléctrica. Olores de toda índole — desde heces a frituras - agreden el olfato del visitante. Impacta la ausencia total del Estado. No hay un solo servicio público, transporte o una escuela, un puesto policial o de salud. Huérfanos de la sociedad, les queda la creatividad en la in-formalidad, que se manifiesta en la infinidad de puestos de venta de alimentos, de peluqueros, que velan por la autoestima, o de carpinteros y cerrajeros, que construyen un banco, una cama o una silla, etc. Al contrario del 
mercado de la economía liberal-capitalista globalizada, la oferta y la demanda acontecen aquí entre iguales.

Sin embargo, después del choque viene la grata sorpresa. Kibera no es solamente eso. África no es sólo un continente que muestra miseria y sufrimiento. Es increíble, pero, al entrar en Kibera, la gente puede dejar el miedo en casa. Una tarde entera caminando por callejuelas repletas de gente, y ningún acto de violencia o agresión, visto o sufrido; ningún pordiosero, al contrario, niños ofreciendo hospitalidad, mujeres sonrientes vendiendo sus productos, jóvenes flirteando animados, viejos sentados, venerados, resueltos a no contar más sus parcos años.

En Kibera conviven veinticuatro pueblos con sus idiomas y culturas propias, algunos de ellos refugiados de países vecinos. Y continúan llegando, de Sudán o de Somalia, porque allí hay lugar y acogida para todos. Todo es desconcertante, sin lógica, un caos no caótico, creativo. La gente entra en Kibera con sentimiento de pena y sale con sentimiento de admiración, pues esa gente remueve las entrañas de misericordia. ¿Cómo saber de dónde les viene la alegría de vivir, la capacidad de acogida, la vitalidad y la fuerza para luchar, el coraje y la esperanza contra toda esperanza? Son los pobres que también interpelan a la fe, al teólogo, a la teología. Se constituyen en principio hermenéutico de la revelación y lugar teológico para hablar de Dios (Jon Sobrino). Son los excluidos, que se erigen en instancia ética, clamando por responsabilidad. No sólo la de los otros, sino, igualmente, la de cada uno de nosotros.

La gente ve y va, aunque impotente, desconcertada, silenciosa, avergonzada por ser Iglesia, a veces, sin entrañas y profetismo, otras veces, con el corazón inquieto y lleno de compasión. No obstante, existe un hilo de esperanza. Los habitantes de Kibera son huérfanos de sociedad, pero no de Iglesia. Huérfanos, pero no solos, ya que les sobra solidaridad y compartir, tal como lo testimonia la presencia cristiana y de otros credos. No se hace mucho, y hasta resultan insignificantes las múltiples iniciativas, que van desde la asistencia a la promoción humana. Aun así, se hace lo esencial, primero dejándose evangelizar por los pobres; después, siendo presencia gratuita, tal como la presencia de Dios en nuestra vida.

En un mundo mercantilizado es edificante ver personas con la osadía de testimoniar que las cosas más importantes de la vida son aquellas que no sirven para nada, que son imposibles de comprar. Lo esencial resistirá siempre al mercado. Y es fundamental que eso esté siempre presente en los foros de teología, así sea de forma chocante como en Kibera. Los teólogos no pueden hacer de la academia un lugar teológico. Si los pobres y su mundo no se constituyen en el locus theologicus por excelencia, la teología habrá dejado de cumplir su primera misión: dejar a Dios ser Dios, que sigue revelándose en los pobres. 


\subsubsection{La conferencia de Desmond Tutu}

África no es únicamente miseria y sufrimiento. Es sobre todo reserva cultural, espiritual, de valores profundos. En su gente no hay lugar para el pesimismo. Ella es fuente de vitalidad y esperanza. Es mosaico de pueblos, culturas y religiones. De verdaderos héroes, anónimos y reconocidos, referencia ética, como Nelson Mandela. África es también Desmond Tutu, a quien los organizadores del Foro tuvieron la feliz idea de invitar para cerrar los trabajos de la semana.

El arzobispo, teniendo una Biblia en la mano como único bagaje, llegó y fue introducido por Sergio Torres, chileno, quien hizo un paralelo entre Augusto Pinochet - exterminador de esperanza-, y el profeta que se levantó con su pueblo contra el apartheid -heraldo de la esperanza, en un mundo de hermanos de todos los colores. Tal como Nelson Mandela, cuyas décadas de prisión, en lugar de endurecerle el corazón, forjaron un activista humilde y pacífico, Desmond Tutu, como el sándalo, sólo exhala perfume de los golpes sufridos. Sin guardar una gota de odio hacia los blancos, él es un negro sonriente, de un corazón de todos los colores, habitado por la virtud del humor, expresión de la felicidad de Dios.

Durante más de una hora, el obispo negro capturó al auditorio entre carcajadas y lágrimas, reflexión y oración. Tenaz como un roble, confiesa que, a pesar de la larga y tortuosa lucha con su pueblo contra el apatheid, desde el primer momento, jamás dudó de que vencerían, pues estaban ciertos de la presencia de Dios, en medio de ellos. Y Dios no falló, ya que la pasión de Jesús, prolongada en la pasión de negros ignorados por hermanos blancos, se hizo resurrección, en un nuevo orden jurídico. Resurrección, sin embargo, que se procesa en dolores de parto, en lo cotidiano de un largo caminar, haciendo aterrizar, poco a poco, el ideal del reino de Dios en la realidad de una nación, que ensaya vivencias de un mundo de hermanos.

Sin dejarse tentar por los efímeros laureles de la victoria, el obispo negro, de manera realista, se pregunta si África del Sur está hoy mejor que aquella de antes del fin del apartheid. Ayer había blancos que excluían; hoy, en un mundo globalizado, continúa un sistema que segrega y victimiza, que excluye y levanta muros que separan hermanos del mismo color. La lucha es larga y compleja, puesto que si ayer implicó un enorme esfuerzo para hacer explotar el apartheid, que estaba fuera, hoy no es menos fácil superar el apartheid de un sistema inicuo y de actitudes personales, que cargamos dentro de nosotros. De ahí la urgencia y la necesidad de "hacer la revolución como un perdonado" (González Faus). No son solamente los otros, los opresores, quienes necesitan de conversión. También las prácticas liberadoras son tocadas por la condición humana y están marcadas por la incoherencia, los personalismos y los protagonismos. Se requiere humildad para dejar que el mismo ardor que nos mueve a liberar a los otros, 
nos lleve a acoger la gracia que nos libera de nosotros mismos. Y entonces, liberados, podremos ayudar a los otros a liberarse.

\section{Hacer que el Foro resuene en la mente y en el corazón}

Un evento de la importancia del Foro Mundial de Teología y Liberación da qué pensar. Una vez presentados los elementos centrales de una posible crónica de lo ocurrido en Nairobi, no está de más dejarlo resonar en la mente y en el corazón. Apoyados en la imaginación creativa, atrevámonos a explicitar y a dejar resonar el grito sofocado de esa África desconocida y olvidada. Grito, como dijimos antes, lanzado a la racionalidad occidental, a los privilegiados de un planeta enfermo, a los pobres y excluidos de un mundo donde no caben todos, a la Iglesia, a los teólogos y a la teología.

\subsection{Un grito a la racionalidad moderna, técnica e instrumental}

Usualmente vemos a África como símbolo de atraso, del tradicionalismo cultural, al margen de valores y realidades de la modernidad como democracia, tolerancia, ciencia, Estado, partidos políticos, nuevas tecnologías, cibernética, robótica, dominio de la naturaleza, medicina, ingeniería genética, cuestiones de género, consumismo... Y, de hecho, a pesar de siglos de colonialismo occidental, África no se rindió al ambiguo proyecto civilizador moderno, con excepción de sus oligarquías herodianas, que responden a los intereses del gran capital internacional. Resistió, y en la actual crisis de la modernidad, de manera desconcertante, tenemos que admitirlo, no obstante sus gigantescos problemas y retos, en gran medida, ella venció. En suelo africano, no hace mucho ruido la crisis de las utopías, de los metarrelatos, de los paradigmas, de los valores, de sentido, de las ciencias, de la teología, de las religiones institucionales, etc.

Al contrario de lo que ocurre en la civilización moderna occidental, sumergida en una crisis sin precedentes, África, y con ella Asia, goza del privilegio de estar anclada en culturas y experiencias religiosas inmunes a los límites de la razón técnico-instrumental. La reserva cultural y religiosa del continente africano impresiona y llena de esperanza. Su mosaico de pueblos, los más antiguos del planeta, resiste la implantación del Estado moderno, totalmente artificial, en culturas que dividen a unos pueblos y unen a otros por completo diferentes. Muchos de los conflictos locales tienen esta naturaleza. El sistema milenario de toma de decisiones, fundado en una especie de comunitarismo y de veneración a la sabiduría de los más viejos, se halla más allá de la crisis de la democracia representativa, que desde su nacimiento, no dejó de representar a la burguesía. En África, ella sólo contribuyó a que algunos, legal aunque injustamente, se perpetuasen en el poder y chupasen, de modo egoísta, las riquezas de todos.

La racionalidad científica, en su trayectoria moderna, siempre más próxima al poder que a la verdad, tropieza en África con una milenaria sabiduría popular, 
también dotada de un logos crítico, mucho más apta para responder a las cuestiones ligadas a la vida. La propia razón, limitada en el seno de la modernidad al logos griego, frío y calculador, en suelo africano abarca otras razones, como la afectiva, la experiencial, la intuitiva, en fin, bosqueja rasgos de una razón comunicativa. Es como si estuviese en la tercera ilustración, sin pasar por la primera y la segunda.

El otro, visto como amenaza o como mero imperativo ético, en una sociedad utilitarista, en suelo africano - más allá del estereotipo prejuiciado del tribalismo- es instancia de fiesta y esperanza. La hospitalidad es el más sagrado de los valores. El sistema económico neoliberal, fundado sobre la ley de la acumulación, choca con la cultura del compartir y de la solidaridad, aparentemente inconsecuentes y empobrecedoras. El capitalismo en África no funciona. No es propio de sus culturas acumular, ahorrar, explotar, consumir, agredir la naturaleza, una economía financiera, la ley de mercado.

La religión, aprisionada, en el seno de la modernidad, a metarrelatos que no dejan a Dios ser Dios, en África, continúa religando lo divino y lo humano, por medio de una fe vinculada a la vida, al cuerpo y a la naturaleza, que prejuiciada y ofensivamente se califica de "animismo". Los teólogos africanos presentes en el Foro repudiaron esta calificación generalizante e irrespetuosa de verdaderas religiones tradicionales, tan ricas y complejas como toda religión y como alma de una cultura.

En resumen, en el campo de la racionalidad, África, aunque premoderna en muchos aspectos, se encuentra en situación más ventajosa que la civilización occidental. La crisis de la modernidad —una razón estrecha y limitada, utilitarista y secularizante, olvidada de cuestiones centrales de la vida humana como la del sentido y los significantes- está evidenciando que África, desde su pobreza sociológica, tiene mucha riqueza cultural que ofrecer al mundo entero. Posee gran riqueza religiosa, anclada en milenarias y sólidas tradiciones, al contrario de la nueva experiencia religiosa occidental, ecléctica y difusa, esotérica y revestida de un neopaganismo sin valores humanos. Hay muchos valores de la modernidad, ampliamente universalizables, y conquistas que integran el patrimonio cultural de la humanidad. África quiere asimilar esos valores, no prescindir de ellos, pero ya depurados de las exacerbaciones infringidas por la modernidad occidental.

En América Latina y el Caribe, al igual que en África y Asia, el mundo indígena y el afroamericano, si, por un lado, tuvieron la desventura de estar excluidos de los beneficios de la modernidad, por otro, tienen la ventura de estar en una situación privilegiada, fuera del epicentro de la crisis de la modernidad. Frente a la ardua tarea de repensar la razón entre nosotros, estas instancias se erigen como lugares obligatorios a los cuales hay que volver a visitar, como fuentes que guardan la autocomprensión de un ser humano no fragmentado y mercantilizable. 


\subsection{Un grito a los privilegiados de un planeta enfermo}

En África, la constatación del fotógrafo brasileño Sebastião Salgado se hace más evidente. En su peregrinación por los cinco continentes, preparando su exposición Exodus, constató asombrado que el planeta ostenta islas de prosperidad, rodeadas de pobreza por todos lados. Ya casi en todas partes hay un 20 por ciento de privilegiados, viviendo en cierta medida a expensas del 80 por ciento de excluidos, dentro o fuera de su país. De igual modo, cómo no acordarse del sociólogo brasileño Josué de Castro, quien ya en la primera mitad del siglo pasado, en su libro clásico Geografía del hambre, señalaba que la mitad de la humanidad dormía con hambre y la otra mitad dormía con miedo a aquellos que pasaban hambre. Hoy, la situación se ha agravado: dos tercios de la humanidad duermen con hambre y un tercio duerme con miedo a los dos tercios que pasan hambre. Es una bomba de tiempo que, a la larga, podría explotar en violencia o migraciones masivas. De ahí que el sistema vea con alivio masacres como la de Ruanda, el avance vertiginoso de la contaminación por los virus HIV, lo mismo que los cuerpos escuálidos de niños y mujeres, de Somalia o Sudán, agonizando de hambre, pues disminuyen el número de pobres y, en consecuencia, los riesgos de explosión violenta.

Al contrario de lo que ocurre en el seno del sistema darwiniano de la globalización neoliberal, donde la riqueza produce pobreza, en África, felizmente, la pobreza oculta inmensas riquezas. Para comenzar, la inmensa riqueza de la austeridad, de saber vivir con lo necesario y hasta con necesidad. Sabemos que el planeta no soporta por mucho más tiempo el nivel de consumo del 20 por ciento de los privilegiados de la humanidad. Mucho menos una economía de rapiña, que agota en pocos años los recursos naturales de generaciones y generaciones. En poco más de un siglo, este modelo implantado en suelo africano por colonizadores europeos modernos hizo que, ayer unos pocos blancos y hoy unos pocos africanos, accediesen al 20 por ciento de los privilegiados hiperconsumistas, rompiendo el equilibrio de la rica cadena de una biodiversidad gestada durante milenios. Numerosas especies desaparecerán, rompiendo la cadena de la vida. Millones de personas están amenazadas, en su sobrevivencia, por el hambre endémica. Pueblos enteros se sienten obligados a migrar en busca de un refugio, así sea en las inhumanas barriadas pobres de las grandes ciudades. El agua escasea. La desertificación del suelo avanza de manera alarmante.

Muchas pérdidas están perdidas para siempre. Algunas, revertidas. Y otras requieren urgentemente ser evitadas. El riesgo no es sólo que los africanos invadan nuestros países, democratizando las conquistas de la modernidad, que benefician apenas a unos pocos. Después de todo, éste es, al menos, el lado bueno de la migración. Quizás así, obligados, los privilegiados repartirán lo que es de todos. El hecho es que el planeta es la casa común, de todos. Y si el planeta agoniza, no habrá entonces privilegios para privilegiados, todos sucumbirán. Los cambios 
climáticos han dado ya la señal de alarma a los que no querían convencerse de que el hambre de millones, generada por lo superfluo de unos pocos, demuestra la demencia de un modelo cultural y económico insostenible. No se trata simplemente de ajustar o humanizar el sistema, de adoptar un "desarrollo sostenible", porque eso, significaría mantener de nuevo el actual concepto de desarrollo, basado en el progreso ilimitado. Más que repensar el concepto de desarrollo, implica dejarlo de lado, integrando en la cultura y en la economía conceptos como austeridad y cuidado de la naturaleza, en lo cual África tiene mucho que enseñar e inspirar al cristianismo.

Tal vez ahí resida la mayor relevancia de la fe cristiana, en nuestros días. Como decían los santos padres, en particular el obispo capadocio Basilio, lo superfluo es un robo. Hoy podríamos añadir que lo superfluo es, asimismo, la principal amenaza a la viabilidad de la vida humana y sus ecosistemas. Desafortunadamente, el cristianismo perdió su sensibilidad ecológica. No obstante, ésta puede ser rescatada, releyendo el mensaje revelado, estimulados por el Espíritu que sopla más allá de la Iglesia, por medio de ecologistas y humanistas, sin hablar del testimonio de la santidad transconfesional de un Francisco de Asís. Más que a rezar juntos, el rebelde de Asís nos convoca a ser hermanos de la luna, del fuego, del agua o de la tierra. Y, no simplemente con ellos, sino a través de ellos, alabar al Dios creador y cuidar de su obra.

\subsection{Un grito a los pobres, en un mundo donde no caben todos}

Parece paradójico, sin embargo, África es un continente de esperanza, porque allá los pobres, pese a todo, continúan esperando contra toda esperanza. Entre los africanos no hay lugar para el pesimismo o el derrotismo. Como dice Desmond Tutu, en ningún momento piensan que serán derrotados, ya que tienen la certeza de que Dios está con ellos, porque transitan sus caminos. En esta certeza, hallan motivo para la fiesta, para engendrar vida, lo que un determinado modelo socio-económico, ajeno a su cultura, está matando. En la fiesta, encuentran energías para la alegría de vivir con lo necesario o incluso en la necesidad extrema. Por eso, son decididos, tenaces. Parafraseando a Euclides da Cunha, "el negro es un bravo".

La alegría y la fiesta están en la familia, en el trabajo, en la escuela, en la Iglesia, en las calles, en las barriadas pobres. Una alegría que contagia e invita a asociarse a su esperanza. Sobre todo, la de los pobres, quienes saben que en la fuerza de los débiles reside su fortaleza, el ideal de un mundo donde quepan todos. Otro mundo, que, antes de ser posible, es necesario. Ellos saben que un mundo solidario no será una concesión, sino una conquista de los olvidados. Serán los pobres los que harán a los ricos vivenciar el milagro de compartir lo que fue dado para todos. Como decía Dom Hélder Câmara: "Dios no creó el latifundio, sino la reforma agraria, pues dio tierra para todos". En esta perspectiva, 
también los evangelios apuntan hacia la salvación de Jesucristo, que pasa por los pobres. Y — quién sabe- África nos ayudará a salvarnos.

Ese grito de África a los pobres del mundo entero es una convocatria a soñar juntos para hacerlo llegar hasta Dios. El sufrimiento del inocente, tal como el de Job, cuestiona a Dios y espera de él una respuesta. Pero de manera especial, el inocente que sufre tiene el derecho de dirigir su grito a los culpables, a los privilegiados. No es un grito de amenaza, sino de justicia, y es una petición a hacer explotar los muros de la exclusión, de los privilegios, de la alteridad negada, de los silos que almacenan lo superfluo de algunos, que es lo necesario de la mayoría. Los pobres también evangelizan, pues son invitación a compartir, a la solidaridad, a la compasión, en cuanto solidaridad con su sufrimiento. En el contexto actual, dejarse evangelizar por los pobres es camino de salvación personal, social y del planeta. Dejarse evangelizar por África es tender puentes entre continentes, destruir muros de egoísmos, reconciliarse con el cuido de la naturaleza, como verdaderos guardianes que somos, encargados por el propio Creador. Las tecnologías de comunicación, en este particular, pueden ayudar mucho a tejer redes de esperanza entre excluidos de un mundo donde no caben todos y pueden contribuir a la edificación del reino, símbolo de los designios de Dios para toda la humanidad.

\subsection{Un grito a una Iglesia etnocéntrica y monocultural}

El África negra, no obstante su diversidad étnica y cultural, posee una Iglesia blanca, eurocéntrica, etnocéntrica y monocultural. Con todo, una Iglesia que sea autóctona, con rostro propio, forma parte de su sensus fidelium local, aunque los innumerables esfuerzos emprendidos en todas las esferas, incluidos los ámbitos del episcopado y de la comunidad teológica, no hayan desembocado en avances concretos. La Iglesia en África tematizó explícitamente la exigencia de la inculturación del evangelio, de la fe y de la propia Iglesia, en la obra evangelizadora. En décadas pasadas, hubo incluso toda una movilización de las iglesias locales con vistas a un "concilio africano", en su propio suelo, para tratar con mayor autonomía y profundidad las cuestiones específicas y particulares del continente. Sólo se les concedió una "asamblea especial del sínodo de los obispos para África", en Roma, frustrando la legítima iniciativa, expectativa y derecho. Aun así, no desapareció el sueño, aunque de nuevo se anuncia una "segunda asamblea", con el mismo perfil que la anterior y fuera de su territorio.

La Iglesia en África está suficientemente madura para una inculturación del cristianismo, en todas las esferas eclesiales. Y comenzando por lo que parece más urgente para los católicos africanos: la inculturación de la liturgia y los sacramentos. Hay un rico simbolismo en sus culturas, hay expresiones corporales y musicales, así como un lenguaje propio, tan aptos o más que los de la cultura europea o de otros continentes para expresar y celebrar los misterios de la fe. 
Les duele en el alma no poder rezar con el cuerpo, que no les permitan introducir en los ritos sus coreografías festivas, no poder hacer llegar hasta el altar los símbolos de su cotidianidad.

Existe, igualmente, el deseo de inculturar la Iglesia, en cuanto institución, configurando sus estructuras, según el modo de sus culturas, por lo demás, mucho más de comunión y participación que el modo eurocéntrico. La institución eclesial se les aparece como una estructura autoritaria, verticalista, clericalista. Se sueña con inculturar inclusive la arquitectura de sus templos, normalmente construidos conforme a los patrones estéticos de la cultura del misionero extranjero. Aspiran, asimismo, a inculturar los ministerios, abriendo espacio a los laicos y a las mujeres, configurando incluso los ministerios ordenados, de acuerdo con sus matrices culturales. De manera particular, el ministerio del obispo y del presbítero, en su forma de vivir, de vestir, de transportarse, de ejercer el poder y de hablar.

No se puede olvidar que el mensajero también es mensaje; que las estructuras son mensaje; que la arquitectura es mensaje. En fin, son realidades que afectan a la Iglesia, en su carácter de signo sacramental.

Y queda, casi por completo, el reto de la elaboración de una teología contextualizada, en la realidad africana, en lenguaje, pertinencia y método propios. La teología que se reflexiona en los medios oficiales en suelo africano, en gran medida, es una teología reflejo de otros continentes. Como sus cuadros son formados en Europa, se repite lo que se aprendió allí. Hay esfuerzos por transitar caminos propios. Sin embargo, son iniciativas de individuos. Tampoco se quiere ser colonizado de nuevo y adoptar la teología latinoamericana, aun cuando responda mejor que otras a sus desafíos.

África quiere espacio y apoyo para tematizar teológicamente cuestiones vitales, como el encuentro del mensaje revelado y del cristianismo con las culturas y las religiones africanas. En este particular, espacios como el Foro Mundial de Teología son fundamentales, porque posibilitan hacer oír su propia palabra, como aconteció en Nairobi, y ensayar y someter al debate iniciativas más atrevidas con la libertad que el Espíritu les proporciona. A una Iglesia pluricultural corresponde un pluralismo teológico, que lejos de amenazar la unidad de la fe y de la Iglesia, explicita la diversidad que da realismo y dinamismo a la unidad.

\subsection{Un grito a la teología y a los teólogos, cada día más huérfanos de Iglesia y de sociedad}

En Nairobi, las visitas al submundo de las barriadas pobres y de la más extrema pobreza sonaron como una invitación incisiva a los teólogos a no perder de vista que la teología es un "acto segundo", precedido por la práctica de la fe. El imperativo de una teología hermenéutica contextualizada, que se articule 
desde la diversidad de las experiencias eclesiales y de las prácticas sociales, en un mundo cada vez más diferenciado y plural, plantea la cuestión del verdadero lugar de la teología. Una teología como práctica-teórica reflejo de la práctica de los cristianos y de las personas en general, no puede perder de vista su verdadero lugar, que es el "mundo real", como afirma Jon Sobrino. Se trata de lo real de lo cotidiano, donde las comunidades eclesiales están insertas en una sociedad de exclusión estructural y en un contexto cada vez más pluricultural y plurirreligioso. Inclusive en el ministerio de la docencia, el teólogo no puede perder de vista que el verdadero locus theologicus de la teología no es la academia, sino las prácticas de la fe de las comunidades eclesiales, en el corazón de la historia y en la perspectiva de los pobres. Si la academia no estuviese en sintonía y articulación con esas prácticas, la enseñanza puede hacer de la teología una reflexión irrelevante para el mundo de hoy, sustrayendo todo el potencial transformador del mensaje evangélico, la esperanza de los pobres.

En Nairobi, directa o indirectamente, África expresó su preocupación por el distanciamiento gradual de teólogos y estudiantes de teología de aquellas experiencias eclesiales que permitieron a la teología latinoamericana y caribeña, por ejemplo, ser lo que ella es: un "acto segundo", una reflexión de un "acto primero" para las prácticas de los cristianos y de las personas en general. Si las prácticas de las comunidades eclesiales, en el corazón de un mundo cada vez más excluyente y pluralista, no desembocan en la academia, la teología corre el serio riesgo de volver a ser cada vez menos eclesial y más eclesiástica, más repetidora del magisterio que su instancia crítica, más apologética y menos dialógica, en una relación inter y transdisciplinaria. Los años más sombríos de la Iglesia coinciden con aquellos en que la teología fue sometida a una mera instancia de repetición del magisterio. De poco sirve una academia en la Iglesia que se limite a llevar a los alumnos a repetir memorísticamente una teología de manuales, fundamentada en una ciencia amordazada, por miedo a la libre investigación y, sobre todo, divorciada de la causa de los pobres. No existe auténtica teología si un teólogo se vuelve huérfano de Iglesia y de sociedad.

\subsection{A modo de conclusión}

Hacer teología en África significa casi elevar el dolor al concepto de la fe - tan grande es el drama de la situación de la amplia mayoría de la población. En África, pensar, duele, desconcierta, confunde, crea perplejidad. No hay lugar para docetismos, pues en su pueblo está la prolongación, en la historia, de la pasión de Jesús de Nazaret. No hay modo de escapar de la solidaridad, también en el sufrimiento, al contrario de lo que hoy pregonan algunos: una opción por los pobres sin dolor, sin sacrificios, sin martirio. La constelación de mártires latinoamericanos da testimonio de una fe que asume las contradicciones de una situación de injusticia y exclusión, y que tiene responsables. Por eso, les fue segada la vida. 
Pero hacer teología en África no es únicamente dolor y sufrimiento. Es sobre todo caer en la cuenta de que el Espíritu Santo pasó por el continente antes que los misioneros, y sembró "semillas del Verbo", que fructifican en abundantes frutos del reino de Dios, como son la esperanza, la alegría, el compartir y el cuido de la vida y de la naturaleza. Es celebrar la eternidad ya presente en las fiestas litúrgicas o profanas, y que insisten en hacerla presente hasta en los momentos en que todo conspira contra la esperanza.

Si la primera tarea de la teología es dejar a Dios ser Dios, un imperativo para la Iglesia de hoy es dejar a África ser África. Y para los cristianos y no cristianos, adoptar a los negros como hermanos de caminata, en la construcción de otro mundo necesario y posible, donde quepan todos. Lo mismo diríamos de los indígenas, los asiáticos, los palestinos, los afroamericanos, los emigrantes... El futuro ya es ahora realidad, en la precariedad del presente. 